MOTA, J.H.; YURI, J.E.; FREITAS, S.A.C.; RODRIGUES JUNIOR, J.C.; RESENDE, G.M.; SOUZA, R.J. Avaliação de cultivares de alface americana durante o verão em Santana da Vargem, MG. Horticultura Brasileira, Brasília, v. 21, n. 2, p. 234-237, abril/junho 2003.

\title{
Avaliação de cultivares de alface americana durante o verão em Santana da Vargem, MG
}

\author{
José Hortêncio Mota'; ${ }^{1}$ Jony Eishi Yuri'; Silvio A.C. de Freitas²; Juarez C. Rodrigues Junior²; Geraldo M. \\ de Resende ${ }^{3}$; Rovilson J. de Souza ${ }^{1}$ \\ ${ }^{1}$ UFLA, C. Postal 037, 37200-000 Lavras-MG; E.mail: jonyyuri@uol.com.br; ${ }^{2}$ REFRICON, Rod. Regis Bittencourt s/n km 294, 06850- \\ 000 Itapecerica da Serra-SP; ${ }^{3}$ Embrapa Semi-Árido, C. Postal 23, 56300-000 Petrolina-PE
}

\section{RESUMO}

Com o objetivo de avaliar cultivares de alface americana durante o verão, foi conduzido em Santana da Vargem, MG, um experimento contendo 17 cultivares. Utilizou-se o delineamento em blocos casualizados, com 3 repetições. Foram avaliados produtividade total e comercial, comprimento do caule, circunferência da cabeça e sanidade das folhas externas. Pelos resultados verificou-se que, comparativamente, a maioria das cultivares apresentou valores similares a tradicionalmente cultivada, Raider, em termos de produtividade total. Para produtividade comercial, as cultivares Lucy Brown, PSR 5338, PSR 4303, PSR 0110, Empire 2000 e Seeker, não mostraram diferenças significativas da cultivar Raider (333,8 g/planta) com 266,6; 276,1; 293,8; 301,6; 304,4 e 333,8 g/planta, respectivamente. Em relação à circunferência de cabeça, com exceção da cultivar PSR 5338, as demais cultivares com melhores produções comerciais foram estatisticamente semelhantes, variando de 38,7 a $41,5 \mathrm{~cm}$.

Palavras-chave: Lactuca sativa L., produtividade, competição de cultivares.

\begin{abstract}
Evaluation of crisphead lettuce cultivars during the summer in Santana da Vargem, Brazil

Crisphead lettuce cultivars were evaluated during the summer in Santana da Vargem, Brazil. The experimental design was a randomized complete blocks, with 3 replications. Total and commercial yield, stem length, head circumference, and health of the outer leaves from 17 cultivars was evaluated. Most cultivars presented similar results compared to the traditionally cultivated cv. Raider, in terms of total yield. For commercial yield, cultivars Lucy Brown, PSR 5338, PSR 4303, PSR 0110, Empire 2000 and Seeker did not present significant difference from 'Raider' (333.8 g/plant) with $266.6 ; 276.1 ; 293.8 ; 301.6 ; 304.4$; and $333.8 \mathrm{~g} / \mathrm{plant}$, respectively. In relation to head circumference, with exception of cv. PSR 5338, other cultivars with better commercial yield were statistically similar, varying from 38.7 to $41.5 \mathrm{~cm}$.
\end{abstract}

Keywords: Lactuca sativa L., yield, cultivar competition.

\section{(Recebido para publicação em 15 de maio de 2002 e aceito em 19 de março de 2003)}

C Tonsiderada a hortaliça folhosa de maior consumo no país, a alface (Lactuca sativa L.), se destaca como cultura de grande importância econômica e alimentar. Segundo FIBGE (1996), no ano de 1996, o Brasil produziu aproximadamente 260.000 toneladas de alface. Desse total, cerca de 173.000 toneladas foram produzidas no estado de São Paulo, ocupando uma área de 7.859 ha e gerando 6.360 empregos (Meirelles, 1998). Quanto aos seus valores nutricionais, apresenta elevados teores de vitaminas e sais minerais, além de baixo teor de caloria (Katayama, 1993).

Atualmente, com o aumento do número de redes de lanchonetes do tipo "fast-food", vem se destacando um grupo de alface denominada "crisphead lettuce" ou tipo "americana" (Maluf, 2000). Esse destaque se deve, principalmente, às características apresentadas por este grupo. A alface americana se diferencia dos demais grupos por apresentar folhas externas de coloração verde-escura, folhas internas de coloração amarela ou branca, imbricadas, semelhantes ao repolho e crocantes. Apresenta também maior vida pós-colheita, possibilitando o transporte a longas distâncias (Decateau et al., 1995). Em relação à produção de alface americana destinada à rede de lanchonetes McDonald's, o sul de Minas Gerais tem se sobressaído, tornando-se pólo produtor dessa hortaliça, produzindo atualmente cerca de 1000 toneladas brutas por mês. Por tratar-se de uma hortaliça de inverno e o cultivo ter se iniciado recentemente nesta região, diversas são as dificuldades na produção, principalmente se for em condições de verão, época particularmente chuvosa e com elevadas temperaturas. Até o momento, o maior desafio está em selecionar cultivares produtivas, com baixa suscetibilidade ao pendoamento precoce e que apresentem tolerância às doenças foliares durante a época mais quente do ano.

Temperaturas acima de $20^{\circ} \mathrm{C}$ estimulam o pendoamento, que se acelera à medida que a temperatura aumenta (Viggiano, 1990). No caso da alface americana, Sanders (1999) afirma que a temperatura ideal para o seu desenvolvimento está entre 15,5 e $18,3^{\circ} \mathrm{C}$. Temperaturas muito elevadas podem provocar queima de bordas das folhas externas, formar cabeças pouco compactas e também contribuir para a ocorrência de deficiência de cálcio, desordem fisiológica conhecida como "tipburn" (Jackson et al., 1999).

O fotoperíodo também pode afetar o processo de pendoamento sendo que dias longos podem acelerá-lo. Waycott (1995), trabalhando com genótipos de alface, condições fotoperiódicas e temperaturas, mostrou que a temperatura isoladamente não foi suficiente para induzir o pendoamento, ao contrário do fotoperíodo.

A suscetibilidade da alface às doenças é um fator de limitação na produção dessa hortaliça (Davis et al., 1997), sendo conhecidos aproximadamente 75 di- 
ferentes tipos de doenças. Diante deste contexto e pela exigência, cada vez maior, por parte dos consumidores, em se reduzir o uso de defensivos, deve-se enfatizar a obtenção de materiais que apresentem resistência às principais doenças foliares da alface.

Avaliou-se neste estudo cultivares de alface americana quanto a sua produtividade, tolerância ao pendoamento e resistência às doenças foliares sob condições de verão.

\section{MATERIAL E MÉTODOS}

O experimento foi conduzido no município de Santana da Vargem, sul de Minas Gerais, a uma altitude de $850 \mathrm{~m}$, situado a $21^{\circ} 05^{\prime} 15^{\prime}$ ' de latitude Sul e 45³4'00' ' de longitude Oeste. O clima da região é do tipo Cwa com características de Cwb, apresentando duas estações definidas: seca (abril a setembro) e chuvosa (outubro a março), segundo a classificação climática de Köppen. $\mathrm{O}$ tipo de solo predominante na área é classificado como Latossolo Vermelho Distrófico (LVd.).

O delineamento utilizado foi blocos casualizados, com 3 repetições, sendo os tratamentos constituídos por 17 cultivares de alface americana (Lucy Brown, PSR 1114, PSR 1115, PSR 0110, PSR 5338, PSR 1530, Sonoma, PSR 0398, PSR 0810, PSR 4290, PSR 4303, PX 8365, Raider, Empire 2000, PSR 9050, PSR 1904 e Seeker). O semeio foi efetuado em 17/12/01, em bandejas de isopor contendo 200 células, preenchidas com substrato comercial "Plantimax HT". A condução das mudas foi realizada em viveiro até atingirem a idade de 31 dias, quando então foram transplantadas no campo.

A área experimental foi demarcada nos canteiros centrais da área de produção. As parcelas foram padronizadas com 2,1 m de comprimento, onde se possibilitou o plantio de 28 mudas, espaçadas a cada $0,30 \mathrm{~m}$, dentre plantas e 0,35 m entre linhas. Definiu-se como área útil, as duas linhas centrais, onde foram retiradas 6 plantas para análises, descartando-se as duas plantas de cada linha nas extremidades de cada parcela.

Essa área foi previamente corrigida com calcário dolomítico, elevando a saturação por base para $70 \%$ (Raij et al., 1996), e adubada com $65 \mathrm{~kg} \mathrm{ha}^{-1} \mathrm{de} \mathrm{N}$, $600 \mathrm{~kg} \mathrm{ha}^{-1} \mathrm{de}_{2} \mathrm{O}_{5}$ e $256 \mathrm{~kg} \mathrm{ha}^{-1} \mathrm{de} \mathrm{K}_{2} \mathrm{O}$, utilizando como fontes o adubo formulado 04-30-16 e superfosfato simples. Após os adubos serem incorporados ao solo, em cada canteiro instalou-se duas linhas de tubo gotejador, com emissores espaçados a cada $0,30 \mathrm{~m}$ e com vazão de 1,5 L.h ${ }^{-1}$, e posteriormente foram cobertos com "mulching" de coloração preta. Posteriormente, foi instalada, em toda a área, uma estrutura de proteção, constituída de túneis altos, que proporcionava a cobertura de dois canteiros por túnel. Essa estrutura apresentava a altura de $2,00 \mathrm{~m}$ e revestimento de filme plástico, de 4,00 m de largura e 100 micras de espessura, possibilitando a entrada de pessoas sem a necessidade de descobri-la.

O transplante das mudas foi realizado em 17/01/02. Após essa operação, irrigou-se a área por aspersão, diariamente, durante 7 dias, até o instante em que foi observado o pegamento uniforme das plantas. A partir do oitavo dia até o instante da colheita, a irrigação foi realizada, também diariamente, por gotejamento. Juntamente com a irrigação, realizaram-se as adubações de cobertura (fertirrigação), totalizando $40 \mathrm{~kg} \mathrm{ha}^{-1} \mathrm{de}$ $\mathrm{N}$ e $85 \mathrm{~kg} \mathrm{ha}^{-1}$ de $\mathrm{K}_{2} \mathrm{O}$, utilizando-se como fontes uréia e cloreto de potássio.

Quanto ao controle fitossanitário, adotou-se o método padrão utilizado pelo produtor, com pulverizações semanais com produtos à base de oxicloreto de cobre e piretróides.

As colheitas foram efetuadas entre os dias 06 e 09/03/02, à medida que se verificava, para cada cultivar, o máximo desenvolvimento vegetativo, apresentando cabeças comerciais compactas. Momentos antes de se iniciar a colheita, fez-se uma avaliação do estado fitossanitário das plantas, baseada em uma escala visual de notas, variando de 1 a 5 (1 = plantas com as folhas externas altamente atacadas por doenças foliares; 2 = presença abundante de lesões nas folhas externas; 3 = presença moderada de lesões nas folhas externas; 4 = lesões escassas nas folhas externas e, $5=$ plantas com as folhas externas sadias). Para a avaliação da produtividade total, as plantas foram cortadas bem rente ao solo e pesadas em uma balança, marca Filizola. Para a avaliação da produtividade comercial, foram pesadas somente as cabeças comerciais, retirando-se as folhas externas. Após essas avaliações, com o auxílio de uma fita métrica, efetuou-se a medida da circunferência das cabeças comerciais. Em relação ao comprimento de caule, para a avaliação dessa característica cortouse a cabeça da alface longitudinalmente, assim, possibilitando a exposição do caule, em que se efetuou a medição, com uso de uma régua.

Os dados foram submetidos à análise de variância, seguindo esquema sugerido por Pimentel Gomes (1990), sendo as médias comparadas pelo teste de Scott-Knott, ao nível de 5\% de probabilidade.

\section{RESULTADOS E DISCUSSÃO}

A produtividade total diferiu significativamente entre cultivares com variações entre 589,4 a 725,5 g/planta (Tabela 1). Verificou-se comparativamente à cultivar tradicionalmente plantada, "Raider", com 650 g/planta, resultados similares em termos de produtividade total. Esses resultados foram bem superiores aos obtidos por Salatiel et al. (2001), que com a cultivar Lorca, nas condições de Jaboticabal, SP, obtiveram 308,5 g/planta, porém inferiores aos obtidos por Yuri (2000), que com a cultivar Lucy Brown, obteve nas condições do município de Boa Esperança, MG, 972,5 g/planta. No caso da produtividade comercial, as cultivares Lucy Brown, PSR 5338, PSR 4303, PSR 0110, Empire 2000 e Seeker, não mostraram diferenças significativas da cultivar Raider $(333,8 \mathrm{~g} /$ planta) com 266,6; 276,1; 293,8; 301,6; 304,4 e 333,8 g/planta, respectivamente, obtendo desempenhos superiores as demais, entretanto, bem inferiores à produtividade relatada por Yuri (2000) para a cultivar Raider, nas condições de verão, no município de Boa Esperança, de 517,3 g/planta. Embora não tenha sido avaliado o grau de ocorrência, a menor produtividade comercial verificada no presente experimento, provavelmente foi em decorrência da presença de nematóides das galhas (Meloidogyne sp.) na área experimental. 
Tabela 1. Produtividade total e comercial, comprimento de caule, circunferência de cabeça e sanidade de cultivares de alface americana em Santana da Vargem (MG), UFLA, 2002.

\begin{tabular}{|c|c|c|c|c|c|c|c|c|c|}
\hline \multirow{3}{*}{$\frac{\text { Cultivar }}{\text { Sonoma }}$} & \multicolumn{3}{|c|}{ Produtividade (g/planta) } & \multirow{2}{*}{\multicolumn{2}{|c|}{$\begin{array}{c}\text { Comprimento } \\
\text { caule }(\mathrm{cm})\end{array}$}} & \multirow{2}{*}{\multicolumn{2}{|c|}{$\begin{array}{c}\text { Circunferência } \\
\text { cabeça }(\mathrm{cm})\end{array}$}} & \multirow{2}{*}{\multicolumn{2}{|c|}{ Sanidade }} \\
\hline & \multicolumn{2}{|c|}{ Total } & Comercial & & & & & & \\
\hline & 358,3 & c & $150,0 \mathrm{~b}$ & 3,5 & c & 35,0 & $\mathrm{~b}$ & 2,6 & $\mathrm{~b}$ \\
\hline PSR 9050 & 450,0 & $b$ & $227,2 \quad b$ & 5,7 & c & 34,7 & $\mathrm{~b}$ & 2,6 & $b$ \\
\hline PSR 4290 & 487,2 & $b$ & $198,8 \quad b$ & 7,6 & $b$ & 35,6 & $b$ & 4,0 & a \\
\hline PSR 0398 & 490,5 & $b$ & $211,1 \quad b$ & 6,5 & $\mathrm{~b}$ & 35,8 & $\mathrm{~b}$ & 3,0 & $b$ \\
\hline PSR 0810 & 505,0 & $b$ & $231,1 \quad b$ & 8,8 & $b$ & 34,9 & $b$ & 2,3 & $\mathrm{~b}$ \\
\hline PSR 1904 & 513,8 & b & $236,6 \mathrm{~b}$ & 5,5 & c & 36,8 & $\mathrm{~b}$ & 4,3 & a \\
\hline PX 8365 & 538,8 & $b$ & $258,3 \mathrm{~b}$ & 7,2 & $b$ & 36,2 & $b$ & 2,0 & $\mathrm{~b}$ \\
\hline PSR 1530 & 589,4 & a & $255,5 \mathrm{~b}$ & 7,5 & $b$ & 39,0 & a & 4,0 & $a$ \\
\hline PSR 1115 & 603,8 & a & $249,4 \quad b$ & 4,0 & c & 37,5 & $b$ & 4,6 & $a$ \\
\hline PSR 1114 & 625,0 & a & $227,2 \quad b$ & 3,5 & c & 37,0 & $b$ & 4,3 & $a$ \\
\hline Raider & 650,0 & a & 333,8 a & 7,1 & $\mathrm{~b}$ & 38,7 & a & 3,6 & $a$ \\
\hline PSR 4303 & 665,5 & a & 293,8 a & 12,6 & a & 41,5 & a & 3,0 & $b$ \\
\hline Lucy Brown & 668,3 & a & 266,6 a & 5,3 & c & 41,3 & a & 5,0 & $a$ \\
\hline PSR 5338 & 671,1 & a & 276,1 a & 4,7 & c & 37,7 & $\mathrm{~b}$ & 4,6 & $a$ \\
\hline Empire 2000 & 715,5 & a & 304,4 a & 7,0 & $\mathrm{~b}$ & 40,1 & a & 5,0 & $a$ \\
\hline Seeker & 717,2 & a & 333,8 a & 5,4 & c & 40,1 & a & 4,6 & a \\
\hline PSR 0110 & 725,5 & a & 301,6 a & 4,5 & c & 39,8 & a & 5,0 & a \\
\hline$\overline{C V}(\%)$ & 10,38 & & 14,63 & 19,5 & & 3,8 & & 17, & \\
\hline
\end{tabular}

Médias seguidas de mesma letra nas colunas não diferem entre si a 5\% de probabilidade pelo teste de Scott-Knott;

${ }^{1}$ Escala visual de notas variando de 1 (folhas externas altamente atacadas por doenças); 2 (presença abundante de lesões nas folhas externas); 3 (presença moderada de lesões nas folhas externas); 4 (lesões escassas nas folhas externas) a 5 (folhas externas sadias).

Quanto ao comprimento de caule, entre as cultivares com melhor desempenho em produtividade comercial, com exceção das cultivares Raider, PSR 4303 e Empire 2000, as demais, Seeker, Lucy Brown, PSR 5338 e PSR 0110, apresentaram os menores comprimentos, com 5,$4 ; 5,3 ; 4,7$ e $4,5 \mathrm{~cm}$, respectivamente. Valores bem inferiores aos obtidos por Bueno (1998), que com a cultivar Lorca, nas condições de Lavras, apresentou comprimentos de caule variando de 5,6 a $6,8 \mathrm{~cm}$. Neste contexto, salienta-se que comprimentos de caule de maior tamanho como o apresentado pela cultivar PSR 4303 são indesejáveis, em função da finalidade a que se destina o produto.

Em relação à circunferência de cabeça, com exceção da cultivar PSR 5338, as demais cultivares com melhores produções comerciais foram estatisticamente semelhantes, variando de 38,7 a $41,5 \mathrm{~cm}$. Os valores obtidos neste experimento foram inferiores ao observado por Mota (1999), que obteve uma circunferência de cabeça comercial de
46,5 cm, nas condições de Lavras. Em termos de sanidade das folhas externas, verificou-se que a grande maioria das cultivares avaliadas apresentou comportamento semelhante com boa resistência às doenças foliares. Entre as cultivares com as melhores produções, com exceção da cultivar PSR 4303, as demais não diferiram estatisticamente, variando entre 3,6 a 5,0. No entanto, apesar de não terem diferido estatisticamente, observou-se que as cultivares PSR 5338, Seeker, Lucy Brown, Empire 2000, e PSR 0110 com notas 4,6; 4,6; 5,$0 ; 5,0$ e 5,0, respectivamente, obtiveram valores superiores quanto à sanidade, em comparação à cultivar Raider (nota 3,6), tradicionalmente cultivada.

Os resultados de produtividade comercial, resistência ao pendoamento precocidade e resistência a doenças foliares, permitem indicar como orientação geral para uso dos produtores, nas condições do Sul de Minas Gerais, as cultivares PSR 5338, Empire 2000, Seeker e PSR 0110, assim como de for- ma geral consolida a cultivar Raider já tradicionalmente cultivada. Embora a cultivar Lucy Brown, neste trabalho, tenha apresentado resultados satisfatórios quanto à produtividade, resistência ao pendoamento e sanidade, não apresentando diferenças significativas em relação às cultivares mais eficientes, por sua alta suscetibilidade ao pendoamento, comprovado por Mota (2002), deixa de ser viável, apesar de ter sua indicação para o cultivo nos meses mais quentes e chuvosos (Asgrow, 2002).

\section{LITERATURA CITADA}

ASGROW. Semente. Campinas: Asgrow Vegetable Seeds, n. 59, ano 21, 4 p. 2002.

BUENO, C.R. Adubação nitrogenada em cobertura via fertirrigação por gotejamento para a alface americana em ambiente protegido. 1998. 54 p. (Tese mestrado), UFLA, Lavras.

DAVIS, R.M.; SUBBARAO, K.V.; RAID, R.N.; KURTZ, E.A. Compendium of lettuce diseases. St. Paul: The American Phytopathological Society, 1997. 79 p. 
DECATEAU D.R.; RANWALA, D.; McMAHON M.J.; WILSON, S.B. The lettuce growing handbook: botany, field procedures, growing problems, and postharvest handling. Illinois: Oak Brook, 1995. $60 \mathrm{p}$.

FUNDAÇÃO INSTITUTO BRASILEIRO DE GEOGRAFIA E ESTATÍSTICA Censo agropecuário: Sudeste. Rio de Janeiro, 1996. Disponível em: <http://www.sidra.ibge.gov.br/ dowload/f5756.csv>. Acesso em 13 mar. 2000.

JACKSON, L.; MAYBERRY, K.; LAEMMLEN, F.; KOIKE, S.; SCHLUBACK, K. Iceberg lettuce production in California. Disponível em: <http// www.vegetablecrops.ucdavis>. Acesso em 24 out. 1999.

KATAYAMA, M. Nutrição e adubação de alface, chicória e almeirão. In: SIMPÓSIO SOBRE NU TRIÇÃO E ADUBAÇÃO DE HORTALIÇAS, 1990, Jaboticabal. Anais...Piracicaba: POTAFOS, 1993. Cap.4, p.141-148.
MALUF, W.R. Melhoramento genético de hortaliças. Lavras. UFLA, 2000. 183 p. Apostila. MEIRELLES, J.C.S. Classificação de alface. São Paulo: Horti \& Fruti, 1998. (Folders).

MOTA, J.H. Efeito do cloreto de potássio via fertirrigação na produção de alface americana em cultivo protegido. Lavras. 1999. 46 p. Dissertação (Tese mestrado), UFLA, Lavras.

MOTA, J.H.; YURI, J.E.; FREITAS, S.A.C.; RODRIGUES JUNIOR J.C.; RESENDE, G.M.; SOUZA, R.J. Comportamento de cultivares de alface americana quanto à queima dos bordos ("tip-burn") na região sul de Minas Gerais. Horticultura Brasileira, Brasília, v. 20, Suplemento CD-ROM, julho 2002.

PIMENTEL GOMES, F. Curso de estatística experimental. 13. ed. São Paulo: Nobel, 1990. 468 p RAIJ, B.; CANTARELLA, H.; QUAGGIO, J.A.; FURLANI, A.M.C. (eds). Recomendações de adubação e calagem para o Estado de São Paulo. 2.ed. Campinas: IAC, 1996. (IAC. Boletim 100).
SALATIEL, L.T.; BRANCO, R.B.F.; MAY, A.; BARBOSA, J.C.; PAULA, C.M.; CECILIO FILHO, A.B. Avaliação de cultivares de alface em diferentes épocas de plantio, cultivadas em casa de vegetação. Horticultura Brasileira, Brasília, v. 19, Suplemento CD-ROM, julho 2001.

SANDERS, D.C. Lettuce production: Disponível em: $<\mathrm{http} / / \mathrm{www} . c e s . n c s u . e d u /$ depts/hort/hil/hil11.html>. Acesso em 11 out. 1999.

VIGGIANO, J. Produção de sementes de alface. In: CASTELLANE, P.D. (org.) Produção de sementes de Hortaliças. Jaboticabal: FCAV/FUNEP, 1990. p. 1-19.

WAYCOTT, W. Photoperiodic response of genetically diverse lettuce accessions. Journal of American Society for Horticultural Science, v. 120, n. 3, p. 460-467, 1995.

YURI, J.E. Avaliação de cultivares de alface americana em duas épocas de plantio e dois locais do sul de Minas Gerais. Lavras. 2000. 51 p. (Tese mestrado), UFLA, Lavras. 